\title{
Is the right to early intervention being honoured? A study of family experiences with early childhood services.
}

\author{
Kathryn Underwood, PhD* \\ Elaine Frankel, EdD* \\ Karen Spalding, $\mathrm{PhD}^{*}$ \\ Kathleen Brophy, $\mathrm{PhD}^{* *}$ \\ *Ryerson University \\ **University of Guelph
}

Corresponding Author:

Kathryn Underwood

Ryerson University, School of Early Childhood Education

350 Victoria St., Toronto, ON M5B 2K3

(416)979-5000 ext. 2519 (Phone)

kunderwood@ryerson.ca (Email) 


\begin{abstract}
This article presents an empirical study of family interactions with childhood disability and early years services in Ontario, Canada, with a focus on whether the right to early intervention is being honoured. International mandates, national legislation, and local policies have increased global awareness of the rights of children to be provided with environments for optimal healthy development and education, including the right to early intervention. The right to early intervention is articulated by the United Nations in several international declarations and conventions. Article 20 of the Convention on the Rights of the Child (CRC, 1989) was the first convention to use the term disability. It specifically addresses the particular rights of disabled children, with the articulation of the right to "enjoy a full and decent life, in conditions which ensure dignity, promote self-reliance, and facilitate the child's active participation in the community" (A.20, s.1, 1990). Further, the CRC clearly states that children have the right to special care and assistance for both the child and the service providers working with the child. Services are to be delivered free of charge in order to ensure that the child has access to education, training, health care, rehabilitation, preparation for employment, and recreation services. In all cases, these services must consider the fullest social integration and individual development that is consistent with cultural and spiritual beliefs (A.20, s.2-4).
\end{abstract}

Keywords: childhood disability, early years, healthy development, education 
It was not until the more recent Convention on the Rights of Persons with Disabilities (CRPD, 2006) that principles articulated a human rights agenda for inclusive education. For example, the CPRD identifies the right of all children to "access an inclusive, quality and free primary education and secondary education on an equal basis with others in the communities in which they live" (A.24, s.2.b). The rights under the CRPD to education, however, do not make any reference to early childhood. Rather, early identification and intervention are articulated within Article 25 as a right under health. Positioning this right under health could be problematic for young children and their families who are likely to interact more frequently with community childcare and early education programs than with health services because health services are organized around the medicalization of individual characteristics of the child. Children's cultural, social, and individual identities are a product of their social environments (Solomon, 2012), including the service system environment that is subject to rights legislation.

While the rights to early intervention and to inclusive education are enshrined in the CRC and CPRD, there is no mechanism to enact these rights in a local context. According to Wronka (2008), the CRC and CPRD must be considered as part of a triptych of complementary rights documents that, taken together, promote and operationalize human rights. First, the United Nations Charter and the Universal Declaration of Human Rights (1948) are at the centre of human rights frameworks which recognize that discrimination is systematically enacted through individual social, economic, and cultural conditions. These two documents set out the premise of human rights as "inalienable" with the concepts of dignity and equality at the heart of all rights. Second, the documents that lay out the details of specific rights include the CRPD and the CRC. Finally, Wronka describes the mechanisms to monitor the implementation of rights. These tools include the monitoring committees of the UN, country progress reports, world conferences, and action plans. One such monitoring committee is the UN Committee on the Rights of the Child. In 2006 the UN Committee on the Rights of the Child issued General Comment No. 9 on the specific rights of children with disabilities. This comment is an example of a monitoring tool as described in the tryptic of rights documents.

UN Committees can be assisted in monitoring human rights and reducing societal barriers with country-thematic reports and with local reports that rely on the lived experience of individuals who are most directly affected. The Inclusive Early Childhood Service System (IECSS) project in Ontario, Canada aims to understand early childhood education, care, and 
intervention services from the perspectives of families who have children experiencing disability in early childhood. This article presents findings from the larger IECSS study in relation to the principles mandated in the UN conventions as they impact families, children, and the service system. The project provides one opportunity to review data from families experiencing services in their communities in order to monitor human rights, eliminate barriers, and improve access in the actual environments in which children and families live. This article examines whether these rights are honoured in the context of a wealthy, industrialized, and northern country. These findings may be useful in other jurisdictions as an example of a methodological approach to monitoring rights through lived experience, and as an example of some of the barriers to these rights in the context of relative structural privilege, as is the case in Ontario.

\section{Background}

The IECSS project is a partnership between municipalities, community organizations, and university researchers. The project is being conducted in five Ontario communities: the City of Toronto (pop. 2.7 million); City of Hamilton (pop. 500 thousand); Wellington County (pop. 150 thousand); the District of Timiskaming (pop. 32 thousand) and Constance Lake First Nation (pop. 820). These five distinct geographic communities provide a range of contexts to understand

early childhood disability experiences in rural, remote, and urban communities. Participants were recruited in these locales through community and clinical organizations. Ethics approval was sought and given by all partnering universities.

At the start of the study, the province of Ontario was undergoing policy changes related to early childhood education and care. These included the introduction of a full day kindergarten program for 4 and 5-year-olds, new childcare legislation, and changes to disability services (including a review of special needs services, a children's mental health strategy, and reorganized autism services). Therefore, this is a significant time to monitor how the system is functioning for children and families, in part because local governments are being asked to respond to so many changes at one time.

\section{Method}

The IECSS project is a longitudinal study using annual interviews with parents and caregivers of disabled children. In the larger study, we are interviewing participants annually 
over a 3-year period. The larger IECSS project is an Institutional Ethnography that explores institutional responses to childhood disability through the standpoint of children's adult guardians. This article is informed by the larger study, however, the analysis diverges from ethnography. It uses findings from a thematic analysis of the first interviews conducted with participants $(\mathrm{N}=67)$.

Participants in the study live in five different geographic communities across Ontario. The participants in the study have the following range of income: $(\mathrm{N}=27 \leq \$ 30 \mathrm{k} / \mathrm{annum} ; \mathrm{N}=14 \geq 30 \mathrm{k}$ and $\leq \$ 50 \mathrm{k} ; \mathrm{N}=17 \geq \$ 50 \mathrm{k}$ and $\leq \$ 100 \mathrm{k}$; and $\mathrm{N}=6 \geq \$ 100 \mathrm{k})$ ). Languages spoken at home are as follows: $(\mathrm{N}=61$ speak English some of the time; however, $\mathrm{N}=21$ report speaking a language other than English or in addition to English). Their immigration experiences include: ( $\mathrm{N}=58$ lived in Canada for 10 or more years, $\mathrm{N}=9$ for less than 5 years). They can variously access a range of disability services. The children in the study ranged from infancy to age 6 at the time of the first interview, with the average age being 3.35 years. Approximately one-third of our sample in this study identify as being from a First Nation or Métis community, and are included in this analysis of human rights. While we do not discuss the United Nations Declaration on the Rights of Indigenous Peoples (2008) in our analysis for this article, it is referenced in Indigenous specific analyses of these data (Ineese-Nash, Bomberry, Underwood, \& Haché, 2018).

Semi-structured interviews consisted of questions about the family's routines, the child's experiences in institutional and community settings, and the services with which the family has interacted, including any services that they had opted not to use or that they were still waiting to access.

Interviews were analysed using constant comparative analysis to derive thematic codes. Overall, 38 thematic codes were identified in the first interviews. In this paper, we analyse three thematic codes that give us information to answer the question, "is the right to early intervention being honoured in the early childhood education and care system in Ontario?" These themes are family attributes, diagnosis, and family capacity to do institutional work. These themes relate to families' interactions with service systems and the actions and information that allow them to move through the process of early intervention. In addition to a description of the themes, we present examples from the data which illustrate how these themes connect to the enactment of disability rights in everyday interactions. 


\section{Themes}

Using the rights identified from the UN Committee on the CRC and the CRPD, we present the three themes that inform our analysis of the capacity of this system to implement these rights.

Family attributes. Family attributes are those qualities of the family that appear to impact their interactions with intervention services. The attributes that were identified from this theme include income, culture and language, relationships within and between family members, employment and work situations, and extended family support or relationships. These characteristics are largely relational within family and community, and status oriented with regard to how those individuals and families are valued in the broader community. Curran and Runswick-Cole (2013) describe the social relations and circumstances in which children and families feel comfortable as "resilience". The family attributes, then, are factors that create the context for resilience rather than resilience being an individual trait of the child or family.

Diagnosis. The second theme is the function of diagnosis or designation in the system. Our study identified that most families spent time, money, and emotional resources to ensure they had a diagnosis to identify their child's characteristics. This diagnosis was often accompanied by designations that qualified them for service. For example, publicly funded autism services were only accessible with a designation of moderate to severe autism, and families reported that it was critical to have this designation. Some participants describe getting diagnoses and designations that professionals acknowledge may be selected to support service acquisition rather than to fit the child. More than twenty years ago, Slee (1996) referred to "clauses of conditionality" or those categories that allowed educators in school systems to justify decisions about services. Our study indicates that in a similar pattern these categories are used to determine which children can access particular early education and intervention services.

Family capacity to do the work. The third theme is families' work. In this theme, we identify the work that must be done by a family in order to gain access to these services. Our study shows that in order for children to access early intervention services, they will need to have an adult working and advocating on their behalf. This adult is responsible for coordinating information, filling out paperwork, responding to requests for information, advocacy for attention from agencies and professionals, and ensuring that the best interests of the child are considered. This work was almost entirely done by women in our study. Griffin and Smith (2005) note in their 
study of mothers' work in schools that, "we are particularly concerned here with the emergence of a distinctive organization of gender in which, in the middle classes, women came to play a special role vis-a-vis the public school system. The availability of women's unpaid work among the middle classes contributes, we suggest, to the ways in which the public school system comes to operate as an engine of in-equality" (p. 10). We similarly found that this unpaid work was necessary for the early education and intervention 'system' to function.

\section{Application of the Themes in a Rights Analysis}

Applying the three themes, we now turn to specific rights and whether diverse family attributes, diagnoses, and family capacity to engage in the work of the institutions, has an impact on the honouring of rights. Each right that is presented here is articulated by the $\mathrm{CRC}$, and identified in General Comment No. 9 of the Committee on the Rights of the Child, or directly in the Convention on the Rights of Persons with Disabilities. The rights statements are first cited and then an analysis of those rights with examples is presented.

Services appropriate to the child and their family. General Comment No. 9 "According to paragraph 2 of Article 23 States parties to the Convention (CRC) recognize the right of the child with disability to special care and shall encourage and ensure the extension of assistance to the eligible child and those responsible for his or her care. The assistance has to be appropriate to the child's condition and the circumstances of the parents or others caring for the child."

While the discourse of intervention frequently refers to supporting a "child's needs," it is the family attributes that appear to have a significant impact on whether or not early intervention is accessible. For example, if a child is diagnosed with autism and is enrolled in behavioural therapy, we might say that the service they are getting is a direct result of the characteristic of the child and their need. However, our data collectively show that there is not a direct relationship between a disability category and the services that a child will access. In fact, it seems that the services a child is able to access are a direct result of the attributes the family brings to the process and the work that the family does to get those services. This means that the family in many ways defines what the early intervention and care 'system' is for each child. Of course, this is in the context of the freedoms they have to actually access those services (Sen, 2009). This freedom is a direct result of the social conditions of the family. In our study, some of the characteristics of families that impacted whether a family sought early intervention services 
included economic means, geography, education, health of other family members, histories of trauma, skills in relationships, social networks and supports, employment, and many other family experiences.

As an example, one participant's most important interactions were with adult mental health services, children's protection services, and the family courts, while another participant, whose child had a similar clinical profile, was primarily interacting with the library, and speech and language intervention services. In each of these examples, the very nature of the intervention was defined by the social conditions of the family, rather than the "needs" of the child. It is also clear when we look at these patterns of family characteristics and child characteristics, that many of the "needs" arise from interaction with the system itself. For example, a family that is accessing occupational therapy through a clinic may need to be available every Tuesday at $2 \mathrm{pm}$. This family then needs childcare in order to take care of the other children. They also need a car to get to the appointment, and they had to have the ability to read English in order to fill out the forms. If the occupational therapy services were organized differently, the subsequent "needs" might be quite different.

In one example, the parent describes her circumstances as exemplary. This mother notes the following:

It is so incredibly well coordinated. And the really big thing is because I signed the consent for email, sharing of information. So we have a nice email list between myself, the speech and language pathologist, the OT, the developmental paediatrican, the clinical resource person and the childcare. We can coordinate visits, we can coordinate assessments, we can share information, I get reminders and vice versa that there is an appointment today[...]. In the mean time I can go to work, that's the key, I can go to work.

This situation, however, did not arise without a tremendous amount of work and advocacy by the mother. Prior to a diagnosis of autism, the child was in a childcare setting that was not providing any intervention or "special care", to the point that the mother took her child out of the childcare and had to stay home. This mother then sought childcare elsewhere but was denied enrollment in at least three centres before finding the childcare described above.

Preserving identity. The CRPD has a general principle of "respect for the evolving capacities of children with disabilities and respect for the right of children with disabilities to preserve their identities" (CRPD, a.3(h)). 
Our study found that the right of children to preserve their identities is not clearly being weighed in decisions and options that are being offered to parents. Our data suggest that the options that are offered to parents are a function of what is available, rather than what the family wants or what they value. For example, many of the services offered in one community may not be offered in another community. In large urban centres, there are more clinics where therapeutic interventions particularly in speech, behavior, and occupational therapies are offered than in rural or northern communities. This means that the "menu" of services is different depending on where a family lives. In addition, we have a number of families in the study who are able to afford privately funded services and these families appear to have more information about new therapies, more choice about the intensity of the services they get, and they are able to choose multiple services without penalty. Most publicly funded intervention services require a diagnosis before children can even be placed on the waitlist and for most services the waitlists are months, if not years. In addition to the limits placed on the menu of services that families can access, many young children experience disability before it is recognized or identified by medical professionals. Our findings suggest that prior to diagnosis, there are more frequent difficulties in interacting with service agencies, for example, childcare staff asking parents to address behaviour concerns.

One family in our study had difficulty accessing services. The mother called to be placed on a waitlist for speech and language services. When she missed a phone call for intake, her file was closed. Once she had sorted out this problem, she waited several months for a new intake process, only to be assigned to a worker with whom she had a negative history. This history began when the therapist had been present at an assessment meeting for the child who was diagnosed with autism. The therapist said, "Your goal is for him is to be like all the other kids, right?". For the mother, this was inconsistent with her valuing of her child as neurodiverse. The mother's response was, “I can't have him in therapy with someone who is going to be saying things like that in front of him". Even though this mother reported her misgivings about working with someone who had such opposing values regarding her son's development, the agency was not willing to make any changes.

For young children who are developing a sense of self, the integration of a positive selfconcept in relation to disability is critical. While disability advocacy and cultural movements are defining this identity for adults, we do not have the same "disability pride" movement for young 
children. In the example described above, the child is on a waitlist for Intensive Behaviour Intervention, but the mother says she will monitor this program closely for the following reasons:

"I'm not okay with them bullying him into not stimming or bullying him into not doing things that make him look weird because that's not his job. It's not his job to change who he is so that other people don't bully him."

Providing care free of charge. General Comment No. 9 states that "The provision of special care and assistance is subject to available resources and free of charge whenever possible. The Committee urges States parties to make special care and assistance to children with disabilities a matter of high priority and to invest to the maximum extent of available resources in the elimination of discrimination against children with disabilities and towards their maximum inclusion in society.",

Overall, there are many factors that contribute to whether families "qualify" for publicly funded services. These include the textual record with information about "severity" of a disability, diagnosis of a condition that meets the criteria for services, and the ability of a family to travel and schedule appointments at the convenience of the service schedule. In addition, even if a child and family "qualify," there is often not enough service available from the perspective of families. This may result in long wait times for services, or short blocks of services that the family does not think are adequate to actually have any effect. The result is that the majority of families in the study were accessing at least some privately funded services. Some families, who had the financial means, had almost entirely abandoned publicly funded services. Some have returned to countries of origin to access a broader range, more intense, and cheaper services. In other cases, even families with low income would borrow money or use public food and housing services to have funds available for private early intervention. Some even moved to communities where they knew they would have access and qualify for publicly funded services. The overarching theme was that families felt they had no choice because they are repeatedly told that the earlier they intervene, the greater the likelihood that interventions will be successful. They also described wanting to intervene early in order to prepare their children to be active members of their communities. However, some of the services that were the most intensive were the ones that gave parents the message that their children would be better suited to segregated programs.

One mother who was accessing a wide range of private services described what this meant for her family. She said that the publicly funded services do not provide the range of services that 
she can access through private therapies. "I don't exactly know what it is. If it's a lack of interest or if it's a lack of time in knowing what could be benefiting our kids' right?" She says when she goes to the publicly funded agencies that have physiotherapy and occupational therapy only, “they would be telling me oh my god there's all this alternative therapy [...] all the therapies may be an alternative in Canada but [not] in other countries."

Maximum Inclusion. General Comment No. 9 "Measures taken for the implementation of the rights contained in the Convention regarding children with disabilities, for example in the areas of education and health, should explicitly aim at the maximum inclusion of those children in society."

The family attributes, documentation of diagnosis, and family capacity to engage in the work of the institutions are all central to whether a child's right to be included is enacted. The findings of this study identify some of the systemic, as opposed to individual, examples of how rights may be infringed upon even when a child and family are accessing many services. First, the positioning of the right to early identification and intervention under health services in the CRPD is problematic for maximum inclusion of young children and their families. Families are more likely to interact with community childcare and early education programs than with health services which limits access to early identification and intervention. Moreover, health services are organized around the medicalization of individual characteristics of the child. The experience of our participants indicates that because services are placed in health facilities, they are participating in a system that is largely based on a medical model of disability: they must seek diagnosis, get a referral to a specialist, and then engage in rehabilitation. This medicalization undermines the social and relational understandings of disability that are critical to inclusion (Underwood, Valeo, \& Wood, 2012). Inclusive approaches based on a social model of disability, instead seek to maximize participation in society while valuing diversity.

One mother, when asked, said that to make the system inclusive,

"It's not just having the kid with a disability in the classroom and calling it inclusion because that's just a matter of being physically present [...It's when] you see the child for who he is, $[\ldots]$ and how can you adapt the learning and the play so everybody is together. I know it's a big dream and maybe I'm just being naïve about one day that happening, but 
this is a dream of every parent of a child with a disability and that's how we can make even our community a better community."

\section{Discussion}

Our study identifies some of the processes within the system of services that act as barriers to inclusion. The families in our study have described a system of services that is largely driven by diagnostic criteria, or functioning of the child, and less by the social and familial characteristics of the child. Institutions and professionals, therefore, hold tremendous power through the diagnostic process and allocation of services.

Based on our findings that early intervention is currently connected to diagnosis, family attributes, and family work, we suggest that the right to early intervention (CRPD, Article 25, s. b) would be better served in a system that does not rely solely on formal identification as a criteria for gaining access to service. Instead, universal services of childcare and family support should be provided and be prepared to support all children, with or without a diagnosis. These inclusive programs should also be intensive and responsive to the diverse development and the ability of all children. Research supports this view that early identification and intervention programs are most effective when embedded in community care and early education programs (Guralnick, 2011; Odom, Buysse, \& Soukaku, 2011; Dunst, Trivett, \& Hamby, 2007), and when they recognize disability as a social construct (Purdue, 2009).

The CRC and the CRPD are tools that define rights; this study sought to understand how well these defined rights are, in fact, enacted. It is, therefore, important to ask rights-based questions for the purpose of monitoring whether rights are enacted in the everyday as opposed to solely through court proceedings. We believe that the early childhood education and care sector has a contribution to make in enacting the right to inclusive ECEC in three ways. First, given that education begins in early childhood, having education and care opportunities supports children at a critical time in their development. Second, the early childhood education and care sector are more effective than schools at connecting family support, community development, and child development as integrated and equally important outcomes of inclusive practice. Third, parents of young children with disabilities need to be supported along with their children. The ECEC sector, therefore, has the opportunity to embed inclusive values and support healthy interpretations of inclusive practice that children and their families can carry into school. 
The only direct reference to early childhood in the CRPD is the right to early intervention (Article 25, s.b). We believe that this right should be interpreted to mean that all children have a right to appropriate opportunities for development. The broader research evidence clearly identifies that early intervention is most successful when it is embedded in inclusive early childhood education and care settings (Brown \& Guralnick, 2012). Early intervention has been linked to lower rates of special education use, parents who are better prepared to advocate and identify their children's rights, and better child development outcomes (Brown \& Guralnick, 2012; Epley, et al. 2010). More importantly, early intervention takes many forms, and one of the most effective interventions is high-quality childcare itself.

The CRPD acknowledges that "disability is an evolving concept [...] disability results from the interaction between persons with impairments and attitudinal and environmental barriers that hinder their full and effective participation in society on an equal basis with others" (CRPD, Preamble, s. e). Therefore, the UN Committee on the Rights of the Child "... emphasizes that the barrier is not the disability itself but rather a combination of social, cultural, attitudinal and physical obstacles which children with disabilities encounter in their daily lives. The strategy for promoting their rights is, therefore, to take the necessary action to remove those barriers" (A. 1, S. A5). It is within the system of early education and intervention that we recognize some of these barriers.

\section{Acknowledgements}

A version of this paper was first presented at the International Society on Early Intervention (ISEI) conference in Stockholm, Sweden, June 9, 2016. The project is funded by the Corporation of the County of Wellington, SSHRC/CRSH Partnership Development Grant \#890-2014-0096, and Ryerson University Offices, the VP Research and Innovation, and the Faculty of Community Services. 


\section{References}

Brown, S.E., \& Guralnick, M.J. (2012). International human rights to early intervention for infants and young children with disabilities: Tools for global advocacy. Infants \& Young Children. 25, 270-285.

Dunst, C. J., Trivette, C. M., Hamby, D. W. (2007). Meta-analysis of family-centered help giving practices research. Mental Retardation and Developmental Disabilities Research Reviews, (13)4, 370-378.

Curran, T. and Runswick-Cole., K. (Eds) (2013). Disabled children's childhood studies; Critical approaches in a global context. UK: Palgrave-MacMillan.

Epley, P., Gotto, G.S., Summers, J.A., Brotherson, M.J., Turnbull, A.P., \& Friend, A. (2010). Supporting families of young children with disabilities: Examining the role of administrative structures. Topics in Early Childhood Special Education, 30(1), 20-31.

Griffith, A. I. \& Smith, D. E. (2005). Mothering for Schooling. NY: Routledge.

Guralnick, M.J. (2011) Why early intervention works: A systems perspective. Infants and Young Children, 24, 6-28.

Ineese-Nash, N., Bomberry, Y., Underwood, K., \& Hache, A. (2018). Raising a Child within Early Childhood Dis-ability Support Systems. Indigenous Policy Journal, 28(3), 1-14.

Odom, S., Buysse, V. \& Soukaku, E. (2011). Inclusion for young children with disabilities: A quarter century of research perspectives. Journal of Early Intervention, 33(4), 344-356.

Purdue, K. (2009). Barriers to and Facilitators of Inclusion for Children with Disabilities in Early Childhood Education. Contemporary Issues in Early Childhood, 10(2), 133-143.

Slee, R. (1996). Clauses of Conditionality, in L. Barton (Ed.) Disability \& Society: Emerging issues and insights. London: Longman.

Solomon, A. (2012). Far from the tree: Parents, children and the search for identity. NY: Scribner.

UN Committee on the Rights of the Child (CRC), General comment No. 9 (2006): The rights of children with disabilities, 27 February 2007, CRC/C/GC/9, Retrieved from http://www.refworld.org/docid/461b93f72.html [accessed 31 July 2017] 
United Nations Declaration on the Rights of Indigenous Peoples (2008), Retrieved from https://www.un.org/esa/socdev/unpfii/documents/DRIPS_en.pdf 